J. Lake Sci. (湖泊科学), 2019, 31(3): 633-645

DOI 10. 18307/2019. 0303

(c) 2019 by Journal of Lake Sciences

\title{
三峡大坝上下游水质时空变化特征”
}

\author{
张馨月 ${ }^{1}$,马沛明 ${ }^{2}$, 高千红 ${ }^{1},{ }^{\text {严海涛 }}{ }^{1}$, 钱 宝 $^{3 * *}$ \\ ( 1 : 长江水利委员会长江三峡水文水资源勘测局,宜昌 443000) \\ ( 2 : 水利部中国科学院水工程生态研究所水利部水工程生态效应与生态修复重点实验室,武汉 430079) \\ (3: 长江水利委员会水文局,武汉 430010)
}

\begin{abstract}
摘 要: 为探索三峡大坝上下游 (坝上 $99.9 \mathrm{~km}$ 、坝下 $63.0 \mathrm{~km}$ 、全长 $162.9 \mathrm{~km}$ ) 水质时空变化特征, 运用主成分分析和方差 分析对 2016 年近坝段水质时空变化特征进行了分析. 主成分分析表明, 水文因子流量 ( $Q$ )、气温 $(T)$ 、水位 $(Z)$ 和水质因 子 (水温 $(\mathrm{WT}) 、 \mathrm{pH}$ 、电导率 $(\mathrm{EC})$ 、溶解氧 $(\mathrm{DO})$ 、悬浮物 $(\mathrm{SS})$ 、高锰酸盐指数 $\left(\mathrm{COD}_{\mathrm{Mn}_{\mathrm{n}}}\right)$ 、硫酸盐 $\left(\mathrm{SO}_{4}^{2-}\right)$ 、氟化物 $\left(\mathrm{F}^{-}\right)$、总硬 度 ( T-Hard)、硝态氮 $\left(\mathrm{NO}_{3}^{-}-\mathrm{N}\right)$ 、总氮 $(\mathrm{TN})$ 和硒 ( $\left.\mathrm{Se}\right)$ ) 的变化主导着研究区域水质变化; 各采样点主成分得分和双因素方 差分析结果显示研究区域水质因子时间变化主要呈现出季节和不同水库运行时期的差异. 消落期 ( $2-5$ 月), T-Hard、 $\mathrm{F}^{-} 、 \mathrm{SO}_{4}^{2-}$ 和 $\mathrm{EC}$ 是影响河流水质变化的主导因子; 汗期 (7-8 月), $\mathrm{Q} 、 \mathrm{SS} 、 \mathrm{COD}_{\mathrm{Mn}} 、 \mathrm{NO}_{3}^{-}-\mathrm{N} 、 \mathrm{TN}$ 和 $\mathrm{Se}$ 是影响河流水质变化的 主导因子; $\mathrm{T}$ 和 WT 主导着汛末 ( 9 月) 河流水质变化, 并引起了 $\mathrm{DO}$ 等理化特性的变化; 高水位运行期 ( 12 月), $\mathrm{Cl}^{-}$是影响 河流水质变化的主导因子. 现阶段, $\mathrm{DO}$ 、有机污染物 $\left(\mathrm{COD}_{\mathrm{Mn}}\right)$ 、无机盐 $\left(\mathrm{SO}_{4}^{2-}\right.$ 和 $\left.\mathrm{F}^{-}\right)$、营养盐类 $\left(\mathrm{NO}_{3}^{-}-\mathrm{N}\right.$ 和 $\left.\mathrm{TN}\right)$ 、类金属元 素 (Se) 和水体的矿化程度 (T-Hard) 的变化主导着区域水质的变化, 是三峡大坝近坝段水域水质的控制因子. 方差分析表 明, 河流的理化特性 ( DO 、 $\mathrm{pH}$ 和 $\mathrm{SS})$ 、营养盐组分构成 $\left(\mathrm{NH}_{3}-\mathrm{N}\right.$ 和 $\left.\mathrm{NO}_{3}^{-}-\mathrm{N}\right)$ 、无机盐类 $\left(\mathrm{EC}\right.$ 和 $\left.\mathrm{Cl}^{-}\right)$、石油类有机污染物及粪 大肠菌群 (FC) 等指标在坝上与坝下断面存在显著性差异. 气温、水温、降雨、含沙量的季节性影响因素和水库调度运行模 式是影响近坝段水质时间差异的主要因子;空间差异主要受城区污染排放和三峡水库调度引起的坝上和坝下水文和水 动力学条件差异影响. 因此控制研究区域因人类活动等造成的外源性污染, 并针对不同类污染物质的季节变化特征实施 合理的水库运行方式是近坝段水质提升的关键.
\end{abstract}

关键词: 水质;多元分析;时空变化特征;三峡大坝;上下游

\section{Spatial-temporal variations of water quality in upstream and downstream of Three Gorges Dam}

\author{
ZHANG Xinyue $^{1}$, MA Peiming ${ }^{2}$, GAO Qianhong ${ }^{1}$, YAN Haitao ${ }^{1} \&$ QIAN Bao $^{3 * *}$ \\ (1: Three Gorges Hydrology and Water Resources Survey Bureau, Bureau of Hydrology, Changiang Water Resources Com- \\ mission, Yichang 443000, P.R. China) \\ (2: Key Laboratory of Ecological Impacts of Hydraulic-Projects and Restoration of Aquatic Ecosystem of Ministry of Water Re- \\ sources, Institute of Hydroecology, Ministry of Water Resources and Chinese Academy of Sciences, Wuhan 430079, P.R. \\ China)
}

(3: Bureau of Hydrology, Changjiang Water Resources Commission, Wuhan 430010, P.R. China)

\footnotetext{
Abstract: In order to explore the spatio-temporal variations of water quality in the upstream and downstream (99.9 $\mathrm{km}$ upstream and $63.0 \mathrm{~km}$ downstream of the dam, total length $162.9 \mathrm{~km}$ ) of the Three Gorges Dam, principal component analysis and variance analysis were used to analyze the vicinity dam water quality in 2016. Principal component analysis showed that the main factors dominating the water quality changes in the study area were hydrological factors, such as discharge $(Q)$, temperature $(T)$, water level (Z) and water quality factors, such as water temperature (WT), dissolved oxygen (DO), suspended substance (SS), per-

* 国家重点研发计划项目(2016YFA0600901) 和湖北省自然科学基金项目 (2017CFB312) 联合资助. 2018-06-07 收 稿; 2018-09-29 收修改稿. 张馨月 ( 1986 ) ,女, 工程师;E-mail:157130765@ qq.com.

** 通信作者;E-mail: jacber@163.com.
} 
manganate index $\left(\mathrm{COD}_{\mathrm{Mn}}\right)$, sulfate $\left(\mathrm{SO}_{4}^{2-}\right)$, fluoride $\left(\mathrm{F}^{-}\right)$, total hardness ( $\mathrm{T}$-Hard $)$, nitrate nitrogen $\left(\mathrm{NO}_{3}^{-}-\mathrm{N}\right)$, total nitrogen ( TN) and selenium ( $\mathrm{Se}$ ). The principal component scores of each sampling point and two-way ANOVA showed that the time variation of water quality factors in the study area were mainly different in season and operation period of different reservoirs, and the water quality changed in reservoir drawdown period ( February to May) was mainly dominated by T-Hard, $\mathrm{F}^{-}$, $\mathrm{SO}_{4}^{2-}$ and electronic conductivity (EC), while the main leading factors were Q, SS, $\mathrm{COD}_{\mathrm{Mn}}, \mathrm{NO}_{3}^{-}-\mathrm{N}$, TN and Se in flood season (July to August), and the water quality in the end of flood season (September) was dominated by $\mathrm{T}$ and WT, and caused changes in the physical and chemical properties such as DO. In addition, chloride $\left(\mathrm{Cl}^{-}\right)$was the leading factor in the period of high water level (December). At the present stage, changes in DO, organic pollutants $\left(\mathrm{COD}_{\mathrm{Mn}}\right)$, inorganic salts $\left(\mathrm{SO}_{4}^{2-}, \mathrm{F}^{-}\right)$, nutrient salts $\left(\mathrm{NO}_{3}^{-}-\mathrm{N}\right.$ and $\mathrm{TN}$ ), Se and mineralization degree of water ( T-hard) dominate the changes in regional water quality and make the greatest effect to the water quality among all parameters. The analysis of variance showed that the physical and chemical characteristics ( DO, $\mathrm{pH}$ and SS), nutrient composition $\left(\mathrm{NH}_{3}-\mathrm{N}\right.$ and $\left.\mathrm{NO}_{3}^{-}-\mathrm{N}\right)$, inorganic salts $\left(\mathrm{EC}\right.$ and $\left.\mathrm{Cl}^{-}\right)$, petroleum organic pollutants and fecal coliform (FC) of rivers were varied significant in the upstream and downstream of the dam. The seasonal influence factors such as temperature, water temperature, rainfall, sediment concentration and reservoir operation mode were the main factors affecting the time difference of water quality near the dam. The spatial difference were mainly affected by the pollution of urban and the change of hydrological and hydrodynamical conditions by Three Gorges Reservoir operation. Therefore, controlling the exogenous pollution caused by human activities in the study area and implementing a reasonable reservoir operation mode for the seasonal variation characteristics of types of pollutants are the key to water quality improvement in the near dam section.

Keywords: Water quality; multivariate analysis; spatio-temporal distribution characteristics; Three Gorges Dam; upstream and downstream

河流的水质主要受到地质、水文、气象等自然因素周期性波动以及受污染排放、兴水利设施等人类活动而 导致的随机波动两方面的影响 ${ }^{[1]}$. 随着社会经济的发展, 人类活动加剧, 长江水质状况面临巨大压力. 习近平 2018 年 4 月在深入推动长江经济带发展座谈会上再一次强调坚持共抓长江大保护、不搞大开发, 湖北省也提 出了九大行动助推长江大保护, 长江水质状况日趋受到国家和地方政府的重视. 三峡大坝蓄水以来, 形成了三 峡库区河道型水库与坝下天然河道两种形态, 其水质因子也呈现出不同的变化特征,三峡工程为防洪、发电、 航运等带来经济效益的同时, 带来的水环境问题也引起了社会各界学者的关注 ${ }^{[2]}$. 近年来关于三峡水质变化 的研究大多集中在库区支流 ${ }^{[3-4]}$, 对三峡大坝近坝段长江干流的水质缺乏大尺度和多断面时空变化特征研究.

水质监测数据具有长期连续、多站点、多指标的特点, 指标之间的信息通常存在相关性和重叠现象 ${ }^{[5]}$, 如何浓缩这些信息, 关系到准确和高效地对水质进行分析与评价. 多元统计方法中主成分分析 (PCA) 和方 差分析 (ANOVA) 被广泛应用于水质的时空特性分析, 如运用 PCA 对湖泊 ${ }^{[6]}$ 、湿地 ${ }^{[7]}$ 、水库 ${ }^{[8]}$ 、海洋 ${ }^{[9]}$ 、河 流 $^{[10-11]}$ 水质主导因子进行提取, 定性识别污染源, 运用 ANOVA 分析水质因子的时空差异性 ${ }^{[12-13]}$. 这些研究 中大多利用主成分提取水质变化的主导因子, 进而通过主成分得分评价水质好坏, 或单一地对因子载荷进 行分析评判, 而将环境因子载荷系数与样点得分结合起来进行时空特性分析的并不多. 本研究对 2016 年三 峡大坝上下游 $162.9 \mathrm{~km}$ (培石一虎牙滩断面) 的水环境因子特征进行评价和相关性分析, 而后进一步结合 PCA 和 ANOVA, 识别主导研究河段水质变化的主要因子, 判别水质时空差异性, 并对形成时空差异的原因 进行探讨, 旨在为长江干流水质监测数据提供合理的分析评价, 为三峡水库调度、长江持续健康发展提供决 策参考.

\section{1 研究区域与研究方法}

\section{1 研究区域概况}

研究区域河段位于湖北省西南部, 西起长江上游培石 (重庆市与湖北省交界的鳊鱼溪口下 $300 \mathrm{~m}$ ), 东至 长江中游虎牙滩 (宜昌市猇亭区虎牙滩水文断面), 坝上 $99.9 \mathrm{~km}$, 坝下 $63.0 \mathrm{~km}$. 该区域处于中纬度亚热带地 区,属亚热带季风气候,雨热同季,四季分明.

\section{2 研究方法}

1.2.1 样品采集与分析 本研究共布置了 8 个采样断面(图 1), 三峡库区坝上断面分别为培石、官渡口、巴 
东、庙河,三峡大坝下游断面分别为黄陵庙、南津关、宜昌、虎牙滩. 每个断面分别在左岸、中泓、右岸布设 3 条采样垂线, 2016 年每月上旬采样 1 次, 采样方法参考《水环境监测规范》( SL219-2013). 样点名称用断面 字母缩写加月份表示, 培石断面 1-12 月即为 P1 P12, 以此类推, 官渡口为 $\mathrm{G} 1 \sim \mathrm{G} 12$, 巴东为 B1 B12, 庙河 为 $\mathrm{M} 1 \sim \mathrm{M} 12$, 黄陵庙为 HLM1 HLM12, 南津关为 N1 N12, 宜昌为 $\mathrm{Y} 1 \sim \mathrm{Y} 12$, 虎牙滩为 HYT1 HYT12.

监测指标包括气温 $(\mathrm{T})$ 、水位 $(\mathrm{Z})$ 、流量 $(\mathrm{Q})$ 、水温 $(\mathrm{WT}) 、 \mathrm{pH}$ 值、电导率 $(\mathrm{EC})$ 、溶解氧 $(\mathrm{DO})$ 、悬浮物 $(\mathrm{SS})$ 、高锰酸盐指数 $\left(\mathrm{COD}_{\mathrm{Mn}}\right)$ 、五日生化需氧量 $\left(\mathrm{BOD}_{5}\right)$ 、氯化物 $\left(\mathrm{Cl}^{-}\right)$、硫酸盐 $\left(\mathrm{SO}_{4}^{2-}\right)$ 、氟化物 $\left(\mathrm{F}^{-}\right)$、总硬度 $(\mathrm{T}-\mathrm{Hard})$ 、氨氮 $\left(\mathrm{NH}_{3}-\mathrm{N}\right)$ 、硝态氮 $\left(\mathrm{NO}_{3}^{-}-\mathrm{N}\right)$ 、总磷 $(\mathrm{TP})$ 、总氮 $(\mathrm{TN})$ 、硒 $(\mathrm{Se})$ 、砷 $(\mathrm{As})$ 、石油类有机污染物 ( POP) 、粪大肠菌群 ( fecal coliforms, FC) , 共计 22 项. 其中气温、水温、 $\mathrm{pH}$ 值、电导率、溶解氧采用便携式水 质分析仪 HQ40d(美国) 现场测定, 悬浮物采用重量法 (GB/T 11901-1989) 测定, 水位、流量摘自水文三峡 局水情报汛数据,其余指标测定参照国家《地表水环境质量标准》( GB 3838-2002).

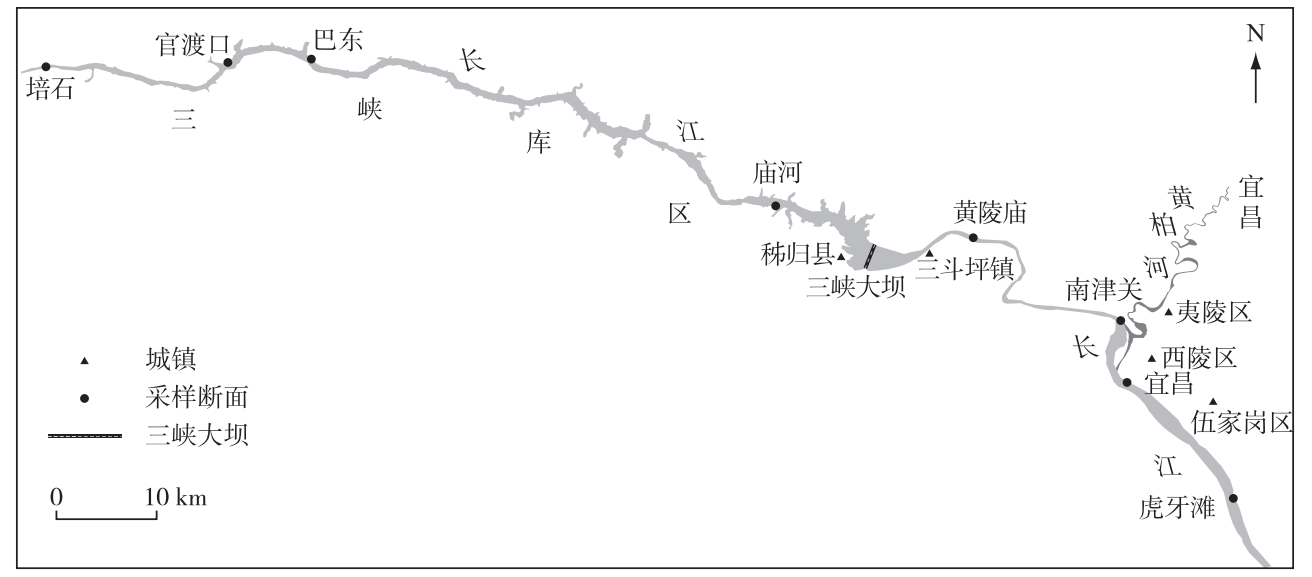

图 1 三峡大坝上下游水质采样断面

Fig.1 Distribution of water sampling sections in upstream and downstream of Three Gorges Dam

1.2 .2 基于多元统计方法的水质特征数据分析 本文首先运用主成分分析方 ${ }^{{ }^{2}}{ }^{[14]}$ 提取引起该流域水质变化 的主导因素并加以分析; 再利用重复测量方差分析 ${ }^{[14]}$ 判别三峡大坝上游与下游不同空间类别上有显著性差 异的水质指标,再在不同空间类别上采用双因素方差分析量化季节变化与水库调度对水质的影响机制,识 别季节变化和水库不同运行时期影响下水质状况的时间差异; 并对主导研究区域水质状况的水质因子时空 差异的潜在因素进行探索分析. 对于低于检出限的 参数,在统计分析时按其方法检出限的半值处理. 主成分分析前, 首先对原始数据进行 KMO 和 Bartlett 球度检验,一般认为 $\mathrm{KMO}>0.7$ 且 $P<0.05$ 时 适合做主成分分析, 为了消除各指标间不同量纲的 影响, 需将原始数据进行 Z-Score 标准化处理 ${ }^{[15]}$ (标 准化数据 $=($ 原数据 - 均值 $) /$ 标准差 ; 溶解氧数据进 行线性变换 ${ }^{[16]}, \mathrm{a}=12, \mathrm{~b}=-1$, 然后再标准化). 对空 间差异显著的水质指标, 分为坝上和坝下两组分别 求年均值, 并对平均值做箱式图进行空间差异直观 分析比较. 双因素方差分析季节划分为春 $(3-5$ 月）、夏 $(6-8$ 月)、秋 $(9-11$ 月)、冬 $(12-2$ 月 $)$, 分别用 $A 、 B 、 C 、 D$ 表示; 三峡水库于每年 9 月上旬 开始蓄水, 11 月初蓄至 $175 \mathrm{~m}, 11$ 月至次年 4 月, 根 据生态、航运等需要逐步消落至 $155 \mathrm{~m}, 5$ 月份加大

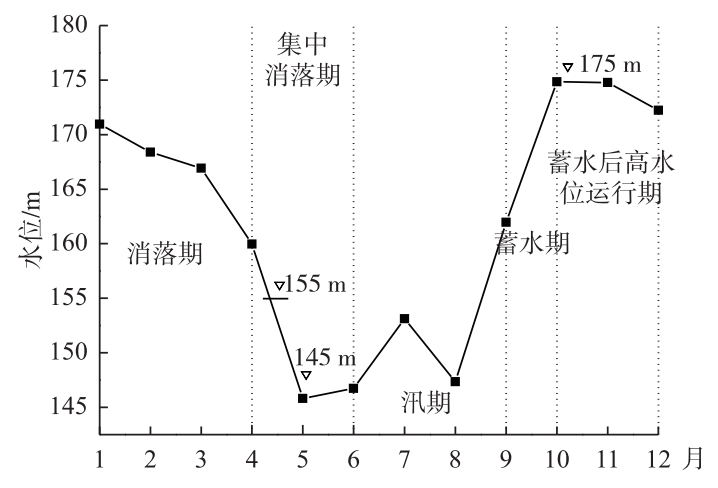

图 22016 年三峡水库坝前水位变化及调度节点

Fig. 2 Water-level fluctuation and scheduling node behind the dam of the Three Gorges Reservoir in 2016 


\section{表 1 研究区域水质因子特征}

Tab.1 Characteristics of water quality factors in the studied area

\begin{tabular}{ccc}
\hline 水质因子 & 均值 \pm 标准差 & 实测值范围 \\
\hline $\mathrm{WT} /{ }^{\circ} \mathrm{C}$ & $19.7 \pm 4.7$ & $12.9 \sim 27.4$ \\
$\mathrm{pH}$ & $7.96 \pm 0.13$ & $7.38 \sim 8.40$ \\
$\mathrm{EC} /(\mu \mathrm{S} / \mathrm{cm})$ & $352.1 \pm 19.4$ & $312.0 \sim 390.0$ \\
$\mathrm{SS} /(\mathrm{mg} / \mathrm{L})$ & $41.7 \pm 38.4$ & $14.0 \sim 236.0$ \\
$\mathrm{COD}_{\mathrm{Mn}} /(\mathrm{mg} / \mathrm{L})$ & $2.1 \pm 0.3$ & $1.8 \sim 3.3$ \\
$\mathrm{BOD}_{5} /(\mathrm{mg} / \mathrm{L})$ & $0.83 \pm 0.12$ & $0.60 \sim 2.70$ \\
$\mathrm{Cl}^{-} /(\mathrm{mg} / \mathrm{L})$ & $13.44 \pm 2.90$ & $6.83 \sim 18.87$ \\
$\mathrm{SO}_{4}^{2-} /(\mathrm{mg} / \mathrm{L})$ & $40.52 \pm 4.64$ & $31.85 \sim 49.26$ \\
$\mathrm{~F}^{-} /(\mathrm{mg} / \mathrm{L})$ & $0.22 \pm 0.03$ & $0.15 \sim 0.27$ \\
$\mathrm{~T}_{-} \mathrm{Hard} /(\mathrm{mg} / \mathrm{L})$ & $146.9 \pm 15.6$ & $112.9 \sim 171.2$ \\
$\mathrm{NH}{ }_{3}-\mathrm{N} /(\mathrm{mg} / \mathrm{L})$ & $0.093 \pm 0.009$ & $0.066 \sim 0.141$ \\
$\mathrm{NO}{ }_{3}^{-}-\mathrm{N} /(\mathrm{mg} / \mathrm{L})$ & $1.683 \pm 0.182$ & $1.289 \sim 2.058$ \\
$\mathrm{TP} /(\mathrm{mg} / \mathrm{L})$ & $0.10 \pm 0.01$ & $0.08 \sim 0.13$ \\
$\mathrm{TN} /(\mathrm{mg} / \mathrm{L})$ & $1.85 \pm 0.17$ & $1.43 \sim 2.21$ \\
$\mathrm{Se} /(\mathrm{mg} / \mathrm{L})$ & $0.001 \pm 0.0004$ & $0.0003 \sim 0.0017$ \\
$\mathrm{As} /(\mathrm{mg} / \mathrm{L})$ & $0.0011 \pm 0.0002$ & $0.0008 \sim 0.0015$ \\
$\mathrm{POP} /(\mathrm{mg} / \mathrm{L})$ & $0.03 \pm 0.01$ & $0.005 \sim 0.090$ \\
$\mathrm{FC} /(\mathrm{ind} . / \mathrm{L})$ & $8178.1 \pm 6405.3$ & $490 \sim 35000$ \\
$\mathrm{DO} /(\mathrm{mg} / \mathrm{L})$ & $7.85 \pm 0.82$ & $6.31 \sim 9.51$ \\
\hline
\end{tabular}

出力运行, 6 月上旬消落至汛限水位 $145 \mathrm{~m}$, 根据水库周 期蓄水方式和 2016 年水库调度水位运行情况 ( 图 2), 三 峡水库运行可以明显划分为消落期 (1-4 月)、集中消落 期 (5-6月)、汛期 ( 7-9 月)、蓄水期 ( 10 月) 和蓄水后 高水位运行期 (11- 12 月) 5 个时期, 分别用 $\mathrm{T} 1 、 \mathrm{~T} 2 、 \mathrm{~T} 3$ 、 $\mathrm{T} 4$ 和 T5 表示, 由于 2016 年 9 月 10 日开始蓄水,而水质 取样在开始蓄水之前, 故把 9 月归为汛期. 上述所有分 析均在 IBM SPSS Statistics 19.0 和 Origin 8.0 软件下 进行.

\section{2 结果与分析}

\section{1 水环境因子特征与评价}

2016 年研究区域水质因子均值和实测范围见表 1 , 研究区域水体呈弱碱性, 根据国家《地表水环境质量标 准》(GB 3838-2002) 基本项目 (FC 除外) 评价标准, 研 究区域水体全年均达到 III 类水标准, 其中汛期 ( 5-10 月)为 III 类水, 非汛期 ( $1-4$ 月, 11- 12 月) 为 II 类水, 整 体水质状况较好. 从实测范围来看, 巴东、庙河、黄陵庙、 虎牙滩断面 POP 出现超 III 类水标准限值的情况, 研究区 域全年 FC 均超 III 类水标准限值 (图 3 ). 水环境因子 Pearson 相关系数矩阵见附表 1 , 其中, $\mathrm{Q}$ 与除 $\mathrm{F}^{-} 、 \mathrm{~T}$-Hard 外的其他因子呈显著相关, 与 $\mathrm{COD}_{\mathrm{Mn}}$ 的正相关性最强, 与 $\mathrm{DO} 、 \mathrm{SO}_{4}^{2-} 、 \mathrm{EC}$ 呈负相关; $\mathrm{DO} 、 \mathrm{SO}_{4}^{2-}$ 与 $\mathrm{WT}$ 表现出极强的显

著负相关; $\mathrm{EC}$ 与 $\mathrm{SO}_{4}^{2-}$ 、T-Hard 呈显著正相关; $\mathrm{COD}_{\mathrm{Mn}}$ 与 $\mathrm{SS}$ 呈极强显著正相关; $\mathrm{F}^{-}$与 $\mathrm{T}-\mathrm{Hard}$ 呈显著正相关; $\mathrm{NO}_{3}^{-}-\mathrm{N}$ 与 $\mathrm{TN} 、 \mathrm{Se}$ 呈极显著正相关, $\mathrm{TN}$ 与 $\mathrm{Se}$ 呈极显著正相关; $\mathrm{Se}$ 与 $\mathrm{As}$ 呈极显著正相关.
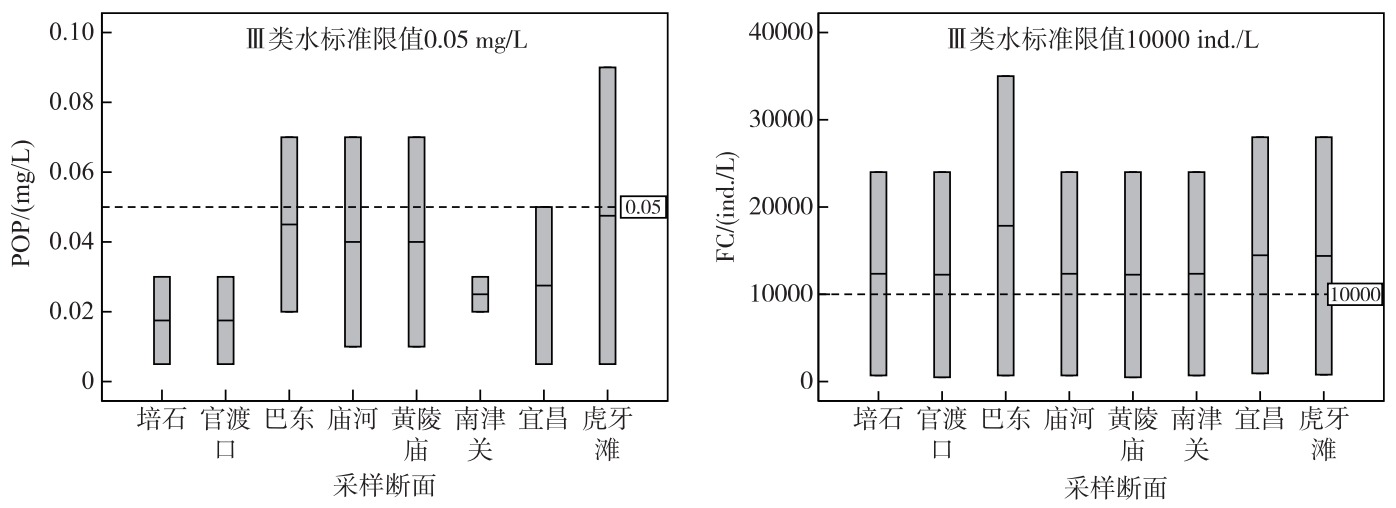

图 3 石油类有机污染物 $(\mathrm{POP})$ 和粪大肠菌群 $(\mathrm{FC})$ 的实测范围

Fig.3 Actual ranges of petroleum organic pollutants (POP) and fecal coliforms (FC)

\section{2 水质主成分分析}

经检验得出, KMO 值为 0.795 且 Bartlett 检验的 $P$ 值小于 0.0001 , 说明原始数据之间有较强的相关关 系, 可以进行主成分分析. 本文按照特征值 $\lambda>1$ 的原则, 提取了引起水质变化的 5 个主成分 (表 2), 其累积 方差贡献率为 $81.511 \%$, 能够充分反映原始数据信息.

由表 2 可知,第 1 主成分 PC1 的方差贡献率最大, 为 $33.182 \%$, 与之关联的主要参数为 $\mathrm{Q} 、 \mathrm{~T} 、 \mathrm{WT} 、 \mathrm{DO} 、$ 
$\mathrm{SS} 、 \mathrm{COD}_{\mathrm{Mn}}$ 和 $\mathrm{SO}_{4}^{2-}$, 反映了水文水动力 $(\mathrm{Q})$ 和气候条件 $(\mathrm{T} 、 \mathrm{WT})$ 的变化对水质的影响, 并引起了河流的理化特 性 $(\mathrm{DO} 、 \mathrm{SS})$ 变化; 人类活动影响下有机污染物 $\left(\mathrm{COD}_{\mathrm{Mn}}\right)$ 和无机盐 $\left(\mathrm{SO}_{42}\right)$ 变化主导着研究区域水质的变化. $\mathrm{COD}_{\mathrm{Mn}}$ 对 PC1 有最强的正相关性, 变化特征明显. 第 2 主成分 PC2 的方差贡献率为 $26.859 \%$, 与之相关联的 主要参数为 $\mathrm{F}^{-} 、 \mathrm{~T}-\mathrm{Hard} 、 \mathrm{NO}_{3}^{-}-\mathrm{N} 、 \mathrm{TN}$ 和 $\mathrm{Se}$, 反映了水体营养盐 $\left(\mathrm{NO}_{3}^{-}-\mathrm{N} 、 \mathrm{TN}\right)$ 、无机污染物 $\left(\mathrm{F}^{-}\right)$和类金属元素 ( Se) 的变化主导着区域水质变化以及水体矿化程度的变化 ( T-Hard); 其中 Se 对 PC2 有最强的正相关性, 表 明其随季节、水文等因素变化明显. 第 3 主成分贡献率为 $9.725 \%$, 与之关联的参数为 $\mathrm{Z}$, 反映了水位涨落对 水质的影响. 第 $4 、 5$ 主成分没有与之相关联大于 0.7 的载荷因子.

表 2 研究区域监测指标主成分分析结果 *

Tab.2 Principle component analysis of monitoring index in the studied area

\begin{tabular}{|c|c|c|c|c|c|}
\hline \multirow{2}{*}{ 监测指标 } & \multicolumn{5}{|c|}{ 主成分 } \\
\hline & PC1 & PC2 & PC3 & PC4 & PC5 \\
\hline 水位 $(Z)$ & -0.128 & -0.007 & -0.723 & 0.420 & 0.022 \\
\hline 流量 $(Q)$ & 0.878 & 0.250 & 0.026 & 0.107 & -0.123 \\
\hline 气温( T) & 0.852 & -0.123 & 0.204 & 0.342 & 0.010 \\
\hline 水温 $(\mathrm{WT})$ & 0.805 & -0.510 & 0.064 & 0.214 & -0.091 \\
\hline $\mathrm{pH}$ & -0.131 & -0.274 & 0.405 & 0.073 & 0.656 \\
\hline 电导率 (EC) & -0.620 & 0.512 & 0.265 & 0.304 & 0.047 \\
\hline 悬浮物 (SS) & 0.865 & 0.183 & -0.242 & -0.160 & 0.210 \\
\hline 高锰酸盐指数 $\left(\mathrm{COD}_{\mathrm{Mn}}\right)$ & 0.904 & 0.164 & -0.166 & -0.121 & 0.219 \\
\hline 五日生化需氧量( BOD $\left._{5}\right)$ & -0.005 & 0.206 & 0.624 & -0.104 & 0.237 \\
\hline 氯化物 $\left(\mathrm{Cl}^{-}\right)$ & -0.490 & -0.622 & 0.124 & 0.183 & -0.075 \\
\hline 硫酸盐 $\left(\mathrm{SO}_{4}^{2-}\right)$ & -0.770 & 0.481 & 0.200 & 0.265 & -0.076 \\
\hline 氟化物 $\left(\mathrm{F}^{-}\right)$ & -0.475 & 0.737 & 0.089 & 0.176 & -0.046 \\
\hline 总硬度 ( T-Hard) & -0.392 & 0.808 & 0.179 & 0.206 & 0.105 \\
\hline 氨氮 $\left(\mathrm{NH}_{3}-\mathrm{N}\right)$ & 0.447 & -0.429 & 0.506 & -0.205 & 0.125 \\
\hline 硝态氮 $\left(\mathrm{NO}_{3}^{-}-\mathrm{N}\right)$ & 0.283 & 0.798 & -0.034 & -0.145 & -0.184 \\
\hline 总磷 ( TP) & 0.412 & 0.699 & 0.092 & 0.160 & 0.256 \\
\hline 总氮 ( TN) & 0.240 & 0.795 & -0.105 & -0.226 & -0.228 \\
\hline 硒 $(\mathrm{Se})$ & 0.277 & 0.918 & -0.029 & -0.056 & 0.032 \\
\hline 砷 (As) & 0.663 & 0.630 & 0.006 & -0.068 & 0.159 \\
\hline 石油类有机污染物 (POP) & 0.029 & -0.054 & 0.497 & -0.404 & -0.499 \\
\hline 粪大肠菌群( FC) & 0.573 & 0.144 & 0.486 & 0.448 & -0.338 \\
\hline 溶解氧 ( DO) & $\mathbf{0 . 7 8 0}$ & -0.334 & 0.062 & 0.430 & -0.159 \\
\hline$\lambda$ & 7.300 & 5.909 & 2.139 & 1.372 & 1.212 \\
\hline 方差贡献率/\% & 33.182 & 26.859 & 9.725 & 6.238 & 5.507 \\
\hline 累积方差贡献率/\% & 33.182 & 60.042 & 69.767 & 76.004 & 81.511 \\
\hline
\end{tabular}

* 黑体数值为环境因子在不同主成分中因子荷载大于 0.7 的值.

为了更清晰地反映研究区域的水质状况, 将各采样点得分和环境因子的载荷系数代替原始数据对水质 进行分析 (图 4), 反映了 3 个方面的信息: (1) 样点在排序空间呈明显的季节分布,逆时针方向来看, 其中 $1-$ 5 月基本聚集在第 3 象限, 6- 8 月在第 4 象限, 9 和 10 月在第 1 象限, 11 和 12 月在第 2 象限; (2) 环境因子 的箭头越长表示其因子载荷越大, 对排序的贡献也越大, 箭头间的夹角表示环境因子间的相关性, 夹角越小 表示相关性越高; 图中箭头较长的环境因子在排序空间中分成 WT、DO、T, SS、COD $\mathrm{Mn}_{\mathrm{n}} 、 \mathrm{Q}, \mathrm{NO}_{3}^{-}-\mathrm{N} 、 \mathrm{TN} 、 \mathrm{Se} 、 \mathrm{As} 、$ $\mathrm{TP}$ 和 T-Hard、 $\mathrm{F}^{-} 、 \mathrm{SO}_{4}^{2-} 、 \mathrm{EC}$ 四簇排列, 主导着研究区域水体水质的变化, 且每簇环境因子间夹角小, 相关性 高. Z、 $\mathrm{POP} 、 \mathrm{pH}$ 、和 $\mathrm{BOD}_{5}$ 的箭头短, 其对排序的贡献小, 样品间的差异小; (3) 将样点向环境因子箭头及其延 长线做投影, 投影位置在箭头指向方向越远则数值越大, 表明该环境因子对其正贡献越大, 反之则越小. 逆 
时针方向看, 第 3 象限中, 箭头指向了排序空间中 $\mathrm{T}-\mathrm{Hard} 、 \mathrm{~F}^{-} 、 \mathrm{SO}_{4}^{2-} 、 \mathrm{EC}$ 变异最大的方向, 可看到 $3-5$ 月 $\mathrm{T}-\mathrm{Hard} 、 \mathrm{~F}^{-} 、 \mathrm{SO}_{4}^{2-} 、 \mathrm{EC}$ 数值高, 主导着水质变化, 7-10 月相对较低;7 月 $\mathrm{Q} 、 \mathrm{SS}, \mathrm{COD}_{\mathrm{Mn}} 、 \mathrm{NO}_{3}^{-}-\mathrm{N} 、 \mathrm{TN} 、 \mathrm{Se}$ 达到最 高值, 主导着 7-8 月各样点的水质变化; 9 月 WT 最高, $2 、 3$ 月份较低, 而 DO 浓度相反 (因 DO 浓度越低反 映水质越差, 分析前对 DO 浓度做了线性转换, 故在图中显示其与水温呈正相关), WT、DO 主导着 9 月各样 点水质变化; 12 月 $\mathrm{Cl}^{-}$浓度全年最高,主导各样点水质变化.

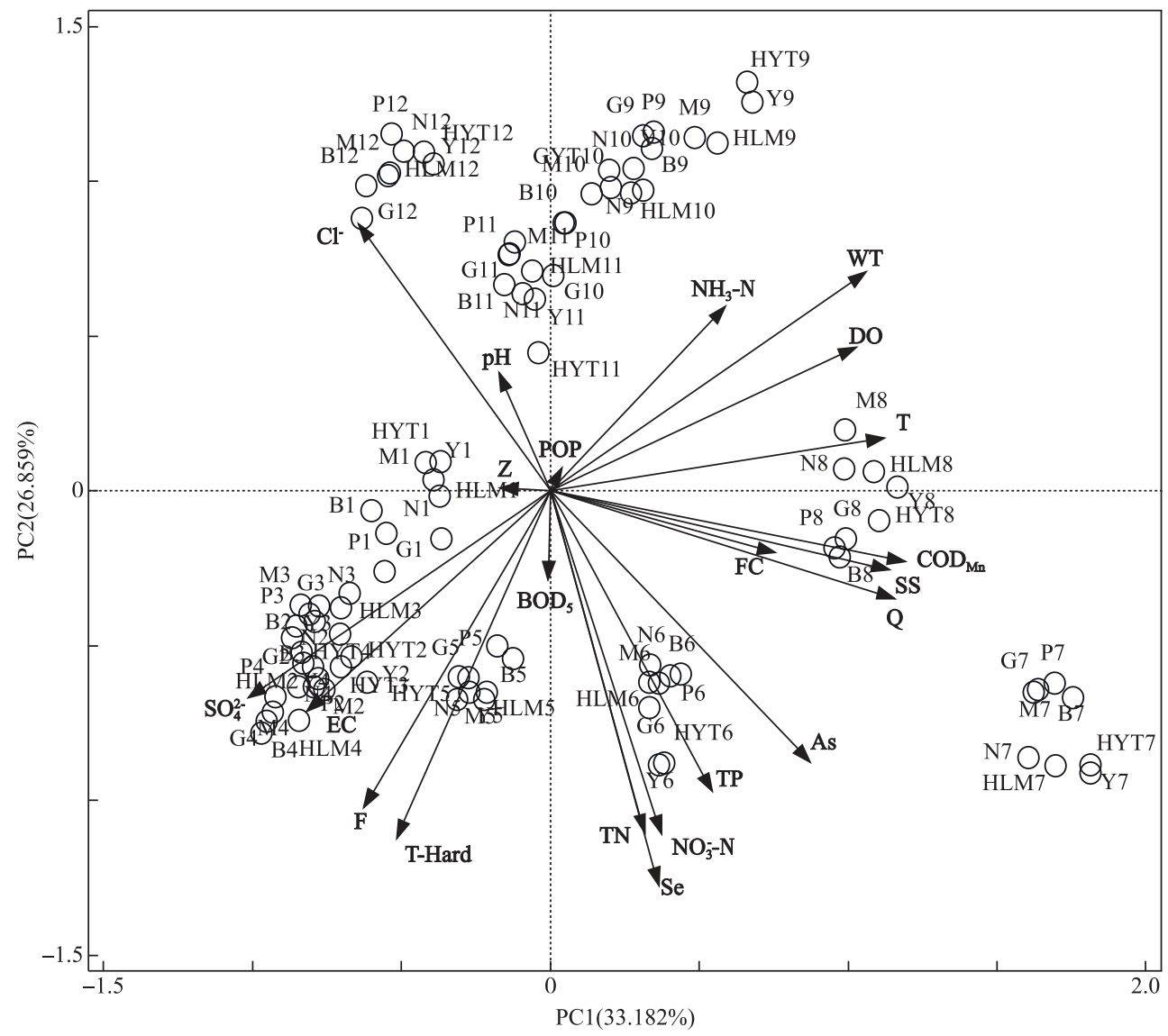

图 4 研究区域水文水环境因子 PCA 分析双序(载荷系数和得分值) 图 (圆圈表示样点,箭头表示环境因子)

Fig.4 The PCA biplots ( scores \& loadings) of hydrology and water quality factors in the research area

\section{3 水质因子时空变化特征}

2.3.1 水质因子空间差异特征分析 本文将坝上和坝下断面分成 2 组对其 $1-12$ 月数据进行重复测量方差 分析, 结果表明, $\mathrm{NH}_{3}-\mathrm{N} 、 \mathrm{NO}_{3}^{-}-\mathrm{N} 、 \mathrm{EC} 、 \mathrm{SS} 、 \mathrm{DO} 、 \mathrm{Cl}^{-} 、 \mathrm{FC} 、 \mathrm{POP} 、 \mathrm{pH}$ 值等水质因子在坝上与坝下断面存在显著性差 异 $(P<0.05)$.

由图 5 可以看出,坝下断面 $\mathrm{NH}_{3}-\mathrm{N} 、 \mathrm{NO}_{3}^{-}-\mathrm{N} 、 \mathrm{DO} 、 \mathrm{FC} 、 \mathrm{POP} 、 \mathrm{pH}$ 值的平均水平要高于坝上断面,坝上断面 $\mathrm{EC} 、 \mathrm{SS} 、 \mathrm{Cl}^{-}$的平均水平显著高于坝下断面. 其中, $\mathrm{NH}_{3}-\mathrm{N} 、 \mathrm{DO}$ 数值在坝上断面较坝下断面均匀集中, 而 $\mathrm{EC} 、$ $\mathrm{Cl}^{-}$等离子水平的数值在坝上断面比坝下断面要分散得多.

2.3.2 水质因子时间差异特征分析 以季节和三峡水库不同运行时期为因子,水质因子为因变量,对坝上和 坝下断面分别进行双因素方差分析. 结果表明 (表 3), 研究区域除 POP 以及坝下断面 $\mathrm{BOD}_{5}$ 以外, 其他水质 因子均随季节或水库运行时期差异显著 $(P<0.01)$, 且季节与水库运行交互作用对水质因子的影响在坝上和 坝下断面基本一致 ( EC 除外). 

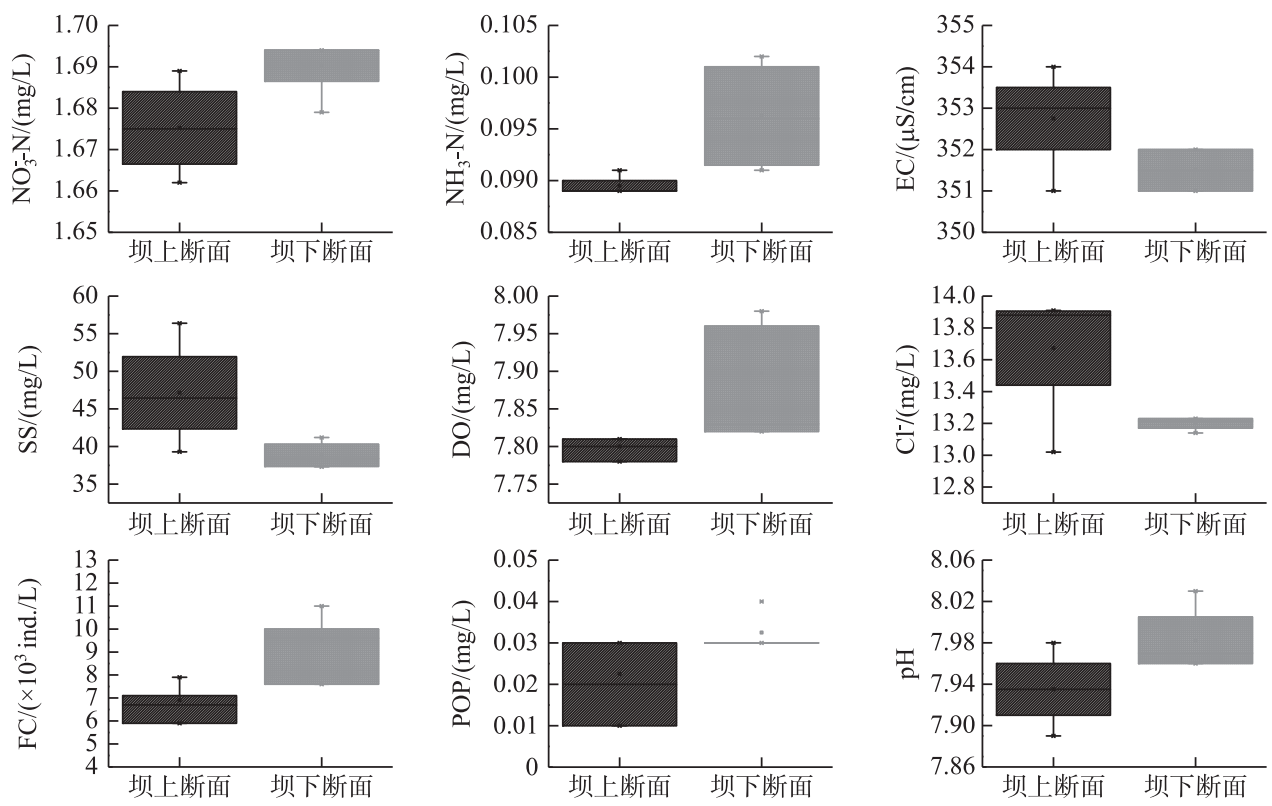

图 5 水质因子的空间差异

Fig.5 Spatial variations of water quality factors

表 3 双因素方差分析显著性检验结果

Tab.3 Two-way ANOVA significance test results

\begin{tabular}{|c|c|c|c|c|c|c|}
\hline \multirow[b]{2}{*}{ 水质因子 } & \multicolumn{3}{|c|}{ 坝上断面 } & \multicolumn{3}{|c|}{ 坝下断面 } \\
\hline & 季节 & 水库运行时期 & $\begin{array}{l}\text { 季节与水库运行 } \\
\text { 时期的交互作用 }\end{array}$ & 季节 & 水库运行时期 & $\begin{array}{l}\text { 季节与水库运行 } \\
\text { 时期的交互作用 }\end{array}$ \\
\hline 电导率 (EC) & $* * *$ & & $* *$ & $* * *$ & $* * *$ & \\
\hline 悬浮物 ( SS) & $* * *$ & $* * *$ & & $* * *$ & $* * *$ & \\
\hline 高锰酸盐指数 $\left(\mathrm{COD}_{\mathrm{Mn}}\right.$ ) & $* * *$ & $* * *$ & & $* * *$ & $* * *$ & \\
\hline 五日生化需氧量 $\left(\mathrm{BOD}_{5}\right)$ & $* * *$ & $* * *$ & & & & \\
\hline 氯化物 $\left(\mathrm{Cl}^{-}\right)$ & $* * *$ & $* *$ & $* * *$ & $* * *$ & $* * *$ & $* * *$ \\
\hline 硫酸( $\left.\mathrm{SO}_{4}^{2-}\right)$ & $* * *$ & $* * *$ & & $* * *$ & $* * *$ & \\
\hline 氟化物 $\left(\mathrm{F}^{-}\right)$ & $* * *$ & $* * *$ & & $* * *$ & $* * *$ & \\
\hline 总硬( T-Hard) & $* * *$ & $* * *$ & $* * *$ & $* * *$ & $* * *$ & $* * *$ \\
\hline 溶解氧( DO) & $* * *$ & $* * *$ & $* *$ & $* * *$ & $* * *$ & $* *$ \\
\hline 氨氮 $\left(\mathrm{NH}_{3}-\mathrm{N}\right)$ & $* * *$ & & & $* *$ & $* *$ & \\
\hline 硝态氮 $\left(\mathrm{NO}_{3}^{-}-\mathrm{N}\right)$ & $* * *$ & & $* * *$ & $* * *$ & $* *$ & $* * *$ \\
\hline 总磷 ( TP) & $* * *$ & & & $* * *$ & & \\
\hline 总氮( TN) & $* * *$ & $* * *$ & $* * *$ & $* * *$ & & $* * *$ \\
\hline 硒(Se) & $* * *$ & $* * *$ & $* * *$ & $* * *$ & $* * *$ & $* * *$ \\
\hline 砷 (As) & $* * *$ & $* * *$ & $* * *$ & $* * *$ & $* * *$ & $* * *$ \\
\hline \multicolumn{7}{|l|}{ 石油类有机污染物 (POP) } \\
\hline 粪大肠菌群( FC) & $* * *$ & $* * *$ & & $* * *$ & $* * *$ & \\
\hline $\mathrm{pH}$ & & $* * *$ & & $* * *$ & $* * *$ & \\
\hline
\end{tabular}

**** 表示差异极显著 $(P<0.001), * *$ 表示差异显著 $(P<0.01)$, 显著水平设为 0.01 .

根据主成分分析的结果, 在时间差异显著的指标中挑选 DO、T-Hard、 $\mathrm{COD}_{\mathrm{Mn}} 、 \mathrm{SO}_{4}^{2-} 、 \mathrm{Se} 、 \mathrm{TN}$ 和 $\mathrm{NO}_{3}^{-}-\mathrm{N} 7$ 个代 
表性指标进一步做季节、水库运行时期及季节和水库运行时期组合平均值间的多重比较,除 $\mathrm{NO}_{3}^{-}-\mathrm{N}$ 外,其他指 标坝上、坝下断面的多重比较结果基本一致,故仅选取坝上断面的多重比较结果为代表进行分析,结果见表 4 .

表 4 季节、水库运行时期及各水平组合的平均值多重比较 *

Tab.4 Multiple comparisons of seasons, reservoir operation periods and average combinations of different levels

\begin{tabular}{|c|c|c|c|c|c|c|c|c|c|}
\hline 指标 & 因素 & $a=0.05$ & 水平组合 & $a=0.05$ & 指标 & 因素 & $a=0.05$ & 水平组合 & $a=0.05$ \\
\hline \multirow[t]{10}{*}{ DO } & D & $\mathrm{a}$ & A:T1 & a & T-Hard & A & a & A:T1 & $\mathrm{a}$ \\
\hline & A & $\mathrm{a}$ & $\mathrm{D}: \mathrm{T} 1$ & $\mathrm{a}$ & & B & $\mathrm{b}$ & A:T2 & $\mathrm{a}$ \\
\hline & C & $\mathrm{b}$ & D:T5 & b & & $\mathrm{D}$ & c & $\mathrm{B}: \mathrm{T} 2$ & $\mathrm{~b}$ \\
\hline & B & c & $\mathrm{A}: \mathrm{T} 2$ & bc & & C & d & D:T1 & $\mathrm{b}$ \\
\hline & & & $\mathrm{C}: \mathrm{T5}$ & $\mathrm{bc}$ & & & & B: T3 & c \\
\hline & $\mathrm{T} 1$ & a & $\mathrm{C}: \mathrm{T} 4$ & c & & $\mathrm{T} 2$ & a & C:T5 & $\mathrm{cd}$ \\
\hline & $\mathrm{T} 5$ & $\mathrm{~b}$ & B: T3 & d & & $\mathrm{T} 1$ & $\mathrm{a}$ & C:T3 & d \\
\hline & $\mathrm{T} 4$ & c & $\mathrm{C}: \mathrm{T} 3$ & d & & $\mathrm{T} 3$ & b & $\mathrm{C}: \mathrm{T} 4$ & $\mathrm{e}$ \\
\hline & $\mathrm{T} 2$ & c & $\mathrm{B}: \mathrm{T} 2$ & d & & $\mathrm{T} 5$ & c & D:T5 & f \\
\hline & $\mathrm{T} 3$ & d & & & & $\mathrm{T} 4$ & d & & \\
\hline \multirow[t]{10}{*}{$\mathrm{COD}_{\mathrm{Mn}}$} & B & a & B: T3 & a & $\mathrm{SO}_{4}^{2-}$ & A & $\mathrm{a}$ & $A: T 1$ & $\mathrm{a}$ \\
\hline & $\mathrm{C}$ & $\mathrm{b}$ & $\mathrm{C}: \mathrm{T3}$ & b & & $\mathrm{D}$ & $\mathrm{b}$ & A:T2 & b \\
\hline & D & c & $\mathrm{B}: \mathrm{T} 2$ & bc & & $\mathrm{C}$ & c & D:T1 & c \\
\hline & A & c & $\mathrm{C}: \mathrm{T} 4$ & $\mathrm{~cd}$ & & B & c & $\mathrm{B}: \mathrm{T} 2$ & c \\
\hline & & & $\mathrm{C}: \mathrm{T5}$ & $\mathrm{cd}$ & & & & D:T5 & $\mathrm{cd}$ \\
\hline & $\mathrm{T} 3$ & $\mathrm{a}$ & D:T5 & $\mathrm{cd}$ & & $\mathrm{T} 1$ & $\mathrm{a}$ & $\mathrm{C}: \mathrm{T} 5$ & de \\
\hline & $\mathrm{T} 2$ & $\mathrm{~b}$ & $\mathrm{~A}: \mathrm{T} 1$ & d & & $\mathrm{T} 2$ & $\mathrm{a}$ & $\mathrm{C}: \mathrm{T} 4$ & ef \\
\hline & $\mathrm{T} 4$ & b & A:T2 & $d$ & & $\mathrm{~T} 5$ & $\mathrm{~b}$ & C:T3 & $\mathrm{fg}$ \\
\hline & $\mathrm{T} 5$ & b & D:T1 & d & & $\mathrm{T} 4$ & b & $\mathrm{B}: \mathrm{T} 3$ & $\mathrm{~g}$ \\
\hline & $\mathrm{T} 1$ & b & & & & $\mathrm{T} 3$ & c & & \\
\hline \multirow[t]{10}{*}{$\mathrm{Se}$} & B & $\mathrm{a}$ & B: $\mathrm{T3}$ & $\mathrm{a}$ & $\mathrm{TN}$ & B & a & B:T3 & a \\
\hline & A & $\mathrm{b}$ & $\mathrm{B}: \mathrm{T} 2$ & $\mathrm{~b}$ & & A & $\mathrm{b}$ & D:T1 & $\mathrm{ab}$ \\
\hline & $\mathrm{D}$ & c & $\mathrm{A}: \mathrm{T} 2$ & $\mathrm{~b}$ & & $\mathrm{D}$ & $\mathrm{b}$ & $\mathrm{A}: \mathrm{T} 2$ & $\mathrm{~b}$ \\
\hline & C & d & A:T1 & $\mathrm{b}$ & & $\mathrm{C}$ & c & A:T1 & bc \\
\hline & & & D:T1 & b & & & & $\mathrm{B}: \mathrm{T} 2$ & c \\
\hline & $\mathrm{T} 2$ & a & $\mathrm{C}: \mathrm{T3}$ & c & & $\mathrm{T} 1$ & a & $\mathrm{C}: \mathrm{T} 4$ & c \\
\hline & $\mathrm{T} 1$ & $\mathrm{ab}$ & $\mathrm{C}: \mathrm{T5}$ & $\mathrm{cd}$ & & $\mathrm{T} 3$ & a & $\mathrm{C}: \mathrm{T} 5$ & d \\
\hline & $\mathrm{T} 3$ & $\mathrm{~b}$ & $\mathrm{C}: \mathrm{T} 4$ & de & & $\mathrm{T} 2$ & a & D:T5 & d \\
\hline & $\mathrm{T} 4$ & c & D:T5 & e & & $\mathrm{T} 4$ & $\mathrm{~b}$ & $\mathrm{C}: \mathrm{T} 3$ & e \\
\hline & T5 & c & & & & $\mathrm{T} 5$ & c & & \\
\hline $\mathrm{NO}_{3}^{-}-\mathrm{N}$ & B & a & B: $\mathrm{T3}$ & a & $\mathrm{NO}_{3}^{-}-\mathrm{N}$ & B & a & B: T2 & a \\
\hline \multirow[t]{9}{*}{ （坝上断面） } & A & $\mathrm{b}$ & $\mathrm{B}: \mathrm{T} 2$ & $a b$ & (坝下断面) & A & $\mathrm{b}$ & $\mathrm{B}: \mathrm{T} 3$ & $\mathrm{ab}$ \\
\hline & $\mathrm{D}$ & $\mathrm{b}$ & A:T2 & $a b$ & & $\mathrm{D}$ & c & $\mathrm{A}: \mathrm{T} 2$ & bc \\
\hline & C & c & D:T1 & $\mathrm{ab}$ & & $\mathrm{C}$ & d & D:T1 & $\mathrm{cd}$ \\
\hline & & & $\mathrm{A}: \mathrm{T} 1$ & bc & & & & A:T1 & d \\
\hline & $\mathrm{T} 2$ & a & $\mathrm{C}: \mathrm{T} 4$ & $\mathrm{~cd}$ & & $\mathrm{~T} 2$ & a & $\mathrm{C}: \mathrm{T5}$ & d \\
\hline & $\mathrm{T} 1$ & a & $\mathrm{C}: \mathrm{T} 5$ & $\mathrm{~cd}$ & & $\mathrm{~T} 3$ & $\mathrm{~b}$ & $\mathrm{C}: \mathrm{T} 4$ & e \\
\hline & $\mathrm{T} 3$ & $\mathrm{ab}$ & D:T5 & d & & $\mathrm{T} 1$ & b & D:T5 & e \\
\hline & $\mathrm{T} 4$ & bc & C:T3 & $\mathrm{e}$ & & $\mathrm{T} 5$ & c & C:T3 & f \\
\hline & T5 & c & & & & $\mathrm{T} 4$ & c & & \\
\hline
\end{tabular}

* 因素和水平组合按平均值从大到小排列; A、B、C、D 分别代表春、夏、秋、冬季; T1 T5 分别代表三峡水库运行的消落期、 集中消落期、汛期、蓄水期和蓄水后高水位运行期; 小写字母为多重比较分析的结果, 相同字母表示因素或组合间不存在 显著性差异, 不同字母表示存在显著性差异. 
由表 4 可知, 春、冬季 $(A 、 D)$ 和消落期 $(T 1)$ 对应的 DO 浓度最高, 交互作用使得 DO 浓度最高值出现在 消落期和春季的组合 $(A: T 1)$, 最低值出现在夏季和集中消落期组合 $(B: T 2)$; 春季 $(A)$ 和整个消落期 $(T 1$ 、 T2) T-Hard 显著高于其他时期, 春季和消落期组合 ( A:T1) T-Hard 最高, 与春季和集中消落期组合 ( A:T2) 差 异不显著, 但显著高于其他水平组合, 最低值出现在冬季高水位运行期组合 (D:T5); $\mathrm{COD}_{\mathrm{Mn}}$ 主要受季节和水 库不同运行时期的主效应影响, 两者的交互作用影响并不显著, 最高值出现在夏季和汛期 ( B、T3), 最低值出 现在春、冬季节; 春季和整个消落期 $\mathrm{SO}_{4}^{2-}$ 浓度显著高于其他时期, 最高值出现在春季和消落期组合 $(\mathrm{A}: \mathrm{T} 1)$, 最低值出现在夏季汛期组合 ( B : T3) ; Se 浓度受季节和水库运行交互作用影响显著,最高值出现在夏季汛期 组合 ( B:T3), 最低值出现在冬季高水位运行期 ( D : T5) 和秋季的蓄水期 ( C:T4) ; 夏季 TN 浓度显著高于其他 季节, 汛期 ( T3 ) 与整个消落期 ( T2、T3) 差异不显著, 但显著高于蓄水期和高水位运行期, 交互作用使得夏季 和汛期组合 ( B : T3) TN 浓度最高, 最低值出现在秋季汛期组合, 即 9 月份; 坝上、坝下断面 $\mathrm{NO}_{3}^{-}-\mathrm{N}$ 浓度最高 值均出现在夏季, 坝下断面集中消落期 ( T2 ) 显著高于其他时期, 受季节与水库运行的交互影响, 坝上断面 $\mathrm{NO}_{3}^{-}-\mathrm{N}$ 最高值出现在夏季汛期组合 ( B : T3), 但差异与春、夏季的消落期并不显著, 而坝下断面最大值出现在 夏季与集中消落期组合 ( B:T2), 与夏季汛期 ( B : T3) 无显著差异. 与 TN 浓度一样, 坝上和坝下断面 $\mathrm{NO}_{3}^{-}-\mathrm{N}$ 浓度最低值均出现在 9 月份.

\section{3 讨论}

\section{1 大坝上下游水质空间变化特征}

三峡大坝蓄水以来近坝段上下游水质空间差异主要表现为河流的理化特性 ( DO 、 $\mathrm{pH}$ 和 $\mathrm{SS}$ )、营养盐组 分构成 $\left(\mathrm{NH}_{3}-\mathrm{N}\right.$ 和 $\left.\mathrm{NO}_{3}^{-}-\mathrm{N}\right)$ 、无机盐类 $\left(\mathrm{EC}\right.$ 和 $\left.\mathrm{Cl}^{-}\right)$、石油类有机污染物及微生物 $(\mathrm{FC})$ 等指标的差异. 大坝建 设后改变了河流的水文、水动力学条件, 对水质也产生了一定影响, 主要表现为水库富营养化、藻类繁殖加 剧、水库盐度增高、水库水温分层的次生影响 ${ }^{[16]}$. 据报道, 韩国锦江建坝后加速了水体的富营养化 ${ }^{[17]}$, 南非 的 Bospoot 大坝, 水库坝前水域出现了明显的水温分层、盐度和电导率随时间升高等问题 ${ }^{[18]}$. 本研究表明, 坝上断面的无机盐 $\left(\mathrm{EC} 、 \mathrm{Cl}^{-}\right)$浓度显著高于坝下断面, 这说明坝上断面的盐度较坝下游天然河道出现升高的 现象. 研究数据显示 ${ }^{[19]}$, 三峡水库蓄水后, 人库沙量远大于出库沙量, 排沙比不到 $50 \%$, 而泥沙对 $\mathrm{Cl}^{-}$等离子 具有较强的吸附作用, 从而导致了坝上和坝下断面 $\mathrm{SS} 、 \mathrm{EC} 、 \mathrm{Cl}^{-}$浓度的差异. 其中坝上断面 $\mathrm{EC} 、 \mathrm{Cl}^{-}$浓度较坝 下断面波动大, 考虑由于坝上断面受上游来水、三峡水库调度等水文和水动力学条件变化的直接影响, 且区 间较长, 泥沙存在区间变化, 导致其 $\mathrm{EC} 、 \mathrm{Cl}^{-}$浓度变化要大于坝下断面, 经三峡水库调节后, 这些因素对坝下 断面的影响要小得多. 双因素方差分析结果也进一步说明坝上断面 EC 受季节和水库调度交互影响显著而 坝下断面并未受到交互影响. 坝下断面 $\mathrm{NH}_{3}-\mathrm{N} 、 \mathrm{NO}_{3}^{-}-\mathrm{N} 、 \mathrm{POP} 、 \mathrm{FC}$ 显著高于坝上断面. 有研究认为 ${ }^{[20]}$, 长江干 流主要污染物来源为城镇生活污水排放和农业污染排放. 坝下断面主要位于城市生活主城区, 且在宜昌和 虎牙滩断面之间有一大型以 $\mathrm{NH}_{3}-\mathrm{N}$ 为主要污染的混合废污水人河排污口, 考虑受城区生活等混合废污水影 响, 坝下游 $\mathrm{NH}_{3}-\mathrm{N} 、 \mathrm{NO}_{3}^{-}-\mathrm{N}$ 等营养盐浓度高于坝上断面. 值得一提的是, 虽然水库中底泥可与磷结合, 对河流 $\mathrm{TP}$ 具有较高的拦截率 ${ }^{[21]}$, 但在此次调查结果坝上断面与坝下断面 TP、TN 浓度并未出现显著差异, 推测与 坝上 SS 浓度高, 颗粒态 N、P 浓度高有关, 而坝下 SS 浓度相对较低, 水中颗粒态 N、P 浓度低, 但坝下断面受 城市污染较坝上断面高, 溶解态 $\mathrm{N} 、 \mathrm{P}$ 浓度高, 故 TP、TN 未出现显著差异, 而表现为营养盐组份构成的差异. 周建军等 ${ }^{[22]}$ 最新研究指出水库大量拦沙拦磷, 水体纳污的缓冲机制被破坏, 使得坝下游溶解磷浓度增加. 另外, 双因素方差分析表明, 坝上断面 $\mathrm{NH}_{3}-\mathrm{N}$ 和 $\mathrm{NO}_{3}^{-}-\mathrm{N}$ 浓度仅受季节影响极显著, 而坝下断面受季节和水 库不同运行时期双因素影响显著 $(P<0.01)$, 因此坝上、坝下营养盐空间差异还受水库调度的影响; 坝下断面 $\mathrm{FC}$ 丰度显著高于坝上断面, 这与江否等 ${ }^{[23]}$ 研究的粪大肠菌群丰度受人类干扰影响显著的结论相符. 三峡水 库调度,不同水位运行下对水质产生了一定的影响 ${ }^{[24]}$, 但近坝段水质状况的空间差异并不如时间差异显著.

\section{2 大坝上下游水质时间变化特征}

主成分与双因素方差分析均表明研究区域大多数水质因子时间变化呈现出季节和不同水库运行时期 的变化特征, 但由于三峡水库以季节周期性的调度方式为主, 故其季节变化对水质因子的影响更大. 其中理 化指标 (DO、T-Hard)、无机盐 $\left(\mathrm{Cl}^{-}\right)$、水体营养盐 $\left(\mathrm{NO}_{3}^{-}-\mathrm{N} 、 \mathrm{TN}\right)$ 、类金属 $(\mathrm{Se} 、 \mathrm{As})$ 等受季节与水库运行交互作 
用的影响极显著 $(P<0.01)$, 表明水温、降雨、含沙量等季节因素与水库调度引起的水文水动力因素之间的交 互作用产生的新效应对这几类水质指标的影响是极其显著的. 主成分分析表明消落期 (2-5 月) 研究区域 水体无机盐类浓度 $\left(\mathrm{F}^{-}\right.$和 $\left.\mathrm{SO}_{4}^{2-}\right)$ 和 T-Hard 较高, 是影响水质变化的主导因子; 流量、泥沙、有机污染物 ( $\mathrm{Q} 、 \mathrm{SS}$ 和 $\mathrm{COD}_{\mathrm{Mn}}$ )、水体营养盐 $\left(\mathrm{NO}_{3}^{-}-\mathrm{N}\right.$ 和 $\mathrm{TN}$ ) 和类金属 $(\mathrm{Se})$ 主导汛期 (7-8 月) 水质变化; 气温、水温等气象因子 是汛末 (9 月) 水质变化的主导因子, 并引起了 DO 等理化特性的变化; 高水位运行期 (12 月) $\mathrm{Cl}^{-}$浓度较高, 是影响水质变化的主导因子. 坝上、坝下断面 POP 以及坝下断面的 $\mathrm{BOD}_{5}$ 季节和水库不同运行时期均差异不 显著, $\mathrm{BOD}_{5}$ 反映水体有机耗氧类污染, 其浓度受水体滞留时间 ${ }^{[25]}$ 和水体浑浊度 ${ }^{[26]}$ 等多方面影响, 坝上断面 $\mathrm{BOD}_{5}$ 浓度受水库调度与季节变化直接影响, 而坝下断面为天然河道的水流形态, 单一的季节或水库运行时 期难以识别其变化规律; POP 未表现出明显的时间差异, 可能是因为研究区域位于长江上游与中游的航运 黄金水道,来往船只较多,石油类污染存在较大的随机性.

多重比较分析结果显示, 春季消落期理化指标 DO、T-Hard 均显著高于其他时期, 冬季高水位运行期 T-Hard 显著低于其他时期, 与主成分分析结果一致. T-Hard 与 SS 有极强的负相关性 $(P<0.01)$, 冬季高水位 运行期, 大部分粗颗粒泥沙沉人河底, 可能由于蓄水刚完成, 水中具有较强吸附能力的极细颗粒泥沙还未完 全沉人水底, 钻镁离子被大量吸附, 从而使得水体硬度降低, 而经过消落期长江水体的进一步澄清, 长江自 然背景的硬度达到最大; 有研究发现, $\mathrm{SO}_{4}^{2-}$ 浓度受降雨和蓄、弃水过程等因素影响 ${ }^{[27]}$, 本次监测发现汛期 $\mathrm{SO}_{4}^{2-}$ 浓度最低, 并随着水库蓄水逐渐升高, 在消落期的春季达到最高, 随后急剧降低. $\mathrm{SO}_{4}^{2-}$ 浓度受季节影响极 为显著, 春季雨水较少, 水体离子浓度较高, 同时在高水位运行期之后水中细颗粒泥沙逐渐减少, 水中被泥 沙吸附的 $\mathrm{SO}_{4}^{2-}$ 减少, 使得峰值出现在春季, 随着夏季降雨量增加的稀释作用和泥沙的吸附作用, $\mathrm{SO}_{4}^{2-}$ 浓度迅 速降低, 这也从侧面反映了研究区域 $\mathrm{SO}_{4}^{2-}$ 并非主要来自陆源污染, 另外由于夏季泥沙含量大, 采用离子色谱 仪分析过滤后的样品, 也可能是导致 $\mathrm{SO}_{4}^{2-}$ 夏季浓度低的原因之一; $\mathrm{COD}_{\mathrm{Mn}}$ 常被作为反映受工农业、生活有机 污染物和还原性无机物质污染程度的综合指标 ${ }^{[28]}$, 主成分分析双序图与 Pearson 相关性分析结果一致, 反映 $\mathrm{COD}_{\mathrm{Mn}}$ 与 $\mathrm{SS} 、 \mathrm{Q}$ 之间具有极强的相关性 $(P<0.01)$, 表明水体 $\mathrm{SS}$ 浓度对 $\mathrm{COD}_{\mathrm{Mn}}$ 有直接的影响, 而流量等水力 学条件变化对 $\mathrm{SS}$ 和 $\mathrm{COD}_{\mathrm{Mn}}$ 又有着直接或间接的影响. 有研究表明 ${ }^{[29]}, \mathrm{COD}_{\mathrm{Mn}}$ 与泥沙有着显著的相关性, 在 水体未受污染的情况下, 泥沙及其中有机质浓度决定了 $\mathrm{COD}_{\mathrm{Mn}}$ 浓度大小, 因此夏季长江水体较大的含沙量 是导致汛期 $\mathrm{COD}_{\mathrm{Mn}}$ 浓度高于其他时期的关键因素; $\mathrm{TN} \mathrm{NO}_{3}^{-}-\mathrm{N}$ 营养盐受季节和水库调度交互作用的影响极 显著, 其最大值和最小值分别出现在夏季汛期和汛期初秋 (9 月), 由于汛期来水来沙量大, 水库调度汛期阶 段一方面使汛期 TN 浓度升高, 均衡了与消落期、集中消落期的差异性, 另一方面由于 9 月蓄水前期含沙量 迅速降低, TN 浓度随之迅速下降, 随着蓄水进程的推进, 库区高水位运行, 库区营养盐物质随泥沙沉降, 清 水下泄, 水库运行使秋、冬季 $\mathrm{TN}$ 浓度降低. 而坝下断面集中消落期的 $\mathrm{NO}_{3}^{-}-\mathrm{N}$ 浓度显著高于其他时期, 这也 从侧面反映了水库的集中消落, 下泄流量增加导致坝下 $\mathrm{NO}_{3}^{-}-\mathrm{N}$ 增加. 另外由宜昌水文站 2016 年降雨量观测 数据发现, 出现 $\mathrm{TN} 、 \mathrm{NO}_{3}^{-}-\mathrm{N}$ 浓度低值的 9 月份降雨量全年最低, 而最高值出现的集中消落期和汗期其降雨量 也是全年最高的, 因此除了水库调度的影响外, 因降雨径流的淋溶、冲刷作用带人水体的陆源性营养盐污染 也不容忽视. Se 等类金属在夏季汛期显著高于其他时期, 而最低值出现在蓄水期和高水位运行期, 可能是由 于夏季降雨较多, 使得陆地上 $\mathrm{Se} 、 \mathrm{As}$ 等类金属污染随降雨进人河流, 再加之夏季流量大, 水体紊动强烈, 河 流底质扰动, 底质中的 $\mathrm{Se} 、 \mathrm{As}$ 重新进人水中.

纵向来看, 陈静生等 ${ }^{\left[{ }^{30]}\right.}$ 的研究表明 $1960 \mathrm{~s}-1980 \mathrm{~s}$ 长江中上游水质呈现酸化趋势, 水质变化趋势具体表 现为碱度降低, $\mathrm{SO}_{4}^{2-} 、 \mathrm{Ca}^{2+} 、 \mathrm{Cl}^{-}$和氮化合物浓度升高, 1962-1966 年宜昌断面 $\mathrm{Cl}^{-}$和 $\mathrm{SO}_{4}^{2-}$ 浓度年均值分别为 6.86 和 $16.03 \mathrm{mg} / \mathrm{L}^{[31]}$, 本次 2016 年监测数据分别为 13.23 和 $40.36 \mathrm{mg} / \mathrm{L}$, 呈现明显的上升趋势, 长江中上游 $\mathrm{TN}$ 浓度较 $1960 \mathrm{~s}-1980 \mathrm{~s}$ 也表现了较明显的上升趋势, 总碱度表现为降低的趋势. 长江干流 $1960 \mathrm{~s}$ 与 $2000 \mathrm{~s}$ $\left(2000-2007\right.$ 年 ${ }^{[32]}$ 离子总量全年均值均在 $180 \sim 230 \mathrm{mg} / \mathrm{L}$ 之间, 这反映了随着时间的推移, 长江流域的地 质条件并未发生大的变化, 长江水体未受到严重污染. 戴润泉等 ${ }^{[33]}$ 研究指出三峡水库蓄水前 $(1996-2001$ 年) 库区江段主要污染因子为 $\mathrm{COD}_{\mathrm{Mn}}$ 、总铅、 $\mathrm{NH}_{3}-\mathrm{N}$, 本次主成分分析显示 $\mathrm{COD}_{\mathrm{Mn}}$ 仍是主导近坝段水质的变化 的主要因子, 而 $\mathrm{NH}_{3}-\mathrm{N}$ 不再是主要污染因子, 这也从侧面反映出由于国家保护长江、污染治理力度加大, 工 
业废污水的人江排放得到了有效控制. 三峡水库蓄水初期 ( $2003-2004$ 年), 近坝水域 $\mathrm{DO} 、 \mathrm{COD}_{\mathrm{Mn}} 、 \mathrm{BOD}_{5}$ 等 指标在坝后略有改善, $\mathrm{Cu} 、 \mathrm{As}$ 等重金属和 TP、TN 等营养盐浓度在坝上、坝下断面均降低 ${ }^{[34]}$, 但 TP、TN 浓度 偏高. 随着蓄水进程的推进,最高蓄水位从 $135 \mathrm{~m}$ 升高到 $175 \mathrm{~m}$, 水质状况变化趋势也发生了改变, 如坝上断 面 (培石) DO 和 $\mathrm{NH}_{3}-\mathrm{N}$ 浓度呈下降趋势 ${ }^{[35]}$, 本次监测数据较蓄水后至 2008 年稳中有升, $\mathrm{TN}$ 浓度在库首、库 中呈现明显的上升趋势 ${ }^{[36]}$. 此次分析表明现阶段 (2016 年), DO 、有机污染物 $\left(\mathrm{COD}_{\mathrm{Mn}}\right)$ 、无机盐 $\left(\mathrm{SO}_{4}^{2-} 、 \mathrm{~F}^{-}\right)$、 营养盐类 $\left(\mathrm{NO}_{3}^{-}-\mathrm{N} 、 \mathrm{TN}\right)$ 、类金属元素 $(\mathrm{Se})$ 和水体的矿化程度 ( T-hard) 主导着研究区域的水质变化, 是三峡大 坝近坝段水域水质的控制因子.

\section{4 结论}

1) 研究区域水体全年均达到《地表水水环境质量标准》(GB 3838-2002) III类水标准, 其中汛期 (5-10 月) 为 III 类水, 非汛期 ( $1-4$ 月, 11- 12 月) 为 II 类水,整体水质状况较好. 主成分分析表明研究区域水质主 导因素为水文因子 $Q 、 T 、 Z$ 和水质因子 $W T 、 D O 、 S S 、 \mathrm{COD}_{\mathrm{Mn}} 、 \mathrm{SO}_{4}^{2-} 、 \mathrm{~F}^{-} 、 \mathrm{~T}-\mathrm{Hard} 、 \mathrm{NO}_{3}^{-}-\mathrm{N} 、 \mathrm{TN} 、 \mathrm{Se}$.

$2)$ 水质因子空间差异主要表现为河流的理化特性 ( $\mathrm{DO} 、 \mathrm{pH}$ 和 $\mathrm{SS})$ 、营养盐组分构成 $\left(\mathrm{NH}_{3}-\mathrm{N}\right.$ 和 $\left.\mathrm{NO}_{3}^{-}-\mathrm{N}\right)$ 、 无机盐类 $\left(\mathrm{EC}\right.$ 和 $\left.\mathrm{Cl}^{-}\right)$、石油类有机污染物及微生物 $(\mathrm{FC})$ 等指标的差异.

3) 水质因子时间差异主要呈现出明显的季节和不同水库运行时期的差异. 现阶段 (2016 年) DO 、有机 污染物 $\left(\mathrm{COD}_{\mathrm{Mn}}\right)$ 、无机盐 $\left(\mathrm{SO}_{4}^{2-}\right.$ 和 $\left.\mathrm{F}^{-}\right)$、营养盐类 $\left(\mathrm{NO}_{3}^{-}-\mathrm{N}\right.$ 和 $\left.\mathrm{TN}\right)$ 、类金属元素 $(\mathrm{Se})$ 和水体的矿化程度 ( $\mathrm{T}-$ Hard) 的变化主导着区域水质的变化, 是三峡大坝近坝段水域水质的控制因子, 且绝大多数控制因子 (有机 污染物、无机盐除外)受季节与水库运行调度交互影响极显著, 可见,水库调度与季节的交互效应对近坝段 水质有着不可忽视的作用.

4) 水质因子空间差异主要受城区污染排放和三峡水库调度引起的坝上和坝下断面之间的水文和水动 力学条件差异的影响;时间差异主要受气温、水温、降雨、含沙量的季节性影响因素和水库调度运行模式影 响. 因此控制研究区域因人类活动等造成的外源性污染,并针对不同类污染物质的季节变化特征实施合理 的水库运行方式是近坝段水质提升的关键.

致谢: 感谢长江三峡水文水资源勘测局教授级高级工程师李云中对写作的帮助！

\section{5 附录}

附录 I 见电子版( DOI: 10.18307/2019.0303).

\section{6 参考文献}

[ 1 ] Hong YP. Impact of the construction of the Yangtze Three Gorges Water Control Project on water quality. Water Resources Protection, 1986, (1) : 29-34. [洪一平. 长江三峡水利枢纽兴建对水质的影响. 水资源保护, 1986, (1): 29-34.]

[ 2 ] Wu JG, Huang JH, Han XG et al. Three-Gorges Dam-experiment in habitat fragmentation. Science, 2003, 300(5623): 1239-1240.

[ 3 ] Ye L, Li DF, Tang T et al. Spatial distribution of water quality in Xiangxi River, China. Chinese Journal of Applied Ecolo$g y, 2003,14(11)$ : 1959-1962. [叶麟, 黎道丰, 唐涛等. 香溪河水质空间分布特性研究. 应用生态学报, 2003,14 (11) : 1959-1962.]

[ 4 ] Ran GH, Ge JW, Miao WJ et al. Spatial-temporal differentiation of water quality in Gufu River of Three Gorges Reservoir. Acta Ecologica Sinica, 2013, 33(17) : 5385-5396. [ 由桂花, 葛继稳, 苗文杰等. 三峡库区古夫河水质时空分异特 征. 生态学报, 2013, 33(17): 5385-5396.]

[ 5 ] Wang LJ, Wang X, Liu LS et al. Multivariate analysis of water factors in Dongting Lake. Research of Environmental Sciences, 2013, 26(1) : 1-7. DOI: 10.13198/j.res.2013.01.5.wanglj.005. [王丽婧, 汪星, 刘录三等. 洞庭湖水质因子的 多元分析. 环境科学研究, $2013,26(1): 1-7$.

[ 6 ] Yu Y, Zhang M, Qian SQ et al. Current status and development of water quality of lakes in Yunnan-Guizhou plateau. $J$ Lake Sci, 2010, 22(6) : 820-828. DOI: 10.18307/2010.0603. [于洋, 张民, 钱善勤等. 云贵高原湖泊水质现状及演 变. 湖泊科学, $2010,22(6): 820-828$. ] 
[ 7 ] Li J, Qi PS, Ma Y et al. Phytoplankton community characteristics of the icebound season and its relationship to the environmental variables in the Zhalong Wetland, China. African Journal of Biotechnology, 2011, 10(38) : 7416-7426.

[ 8 ] Shi LD, Zhu WJ, Hu JX et al. Characteristics and influencing factors analysis of spatio-temporal variations of water quality in Tanpu Reservoir and its tributaries. Journal of Hydroeclology, 2013, 34(5) : 9-15. [施练东, 竺维佳, 胡菊香等. 汤 浦水库及人库支流水质时空变化特征与影响因素分析. 生态学杂志, 2013, 34(5): 9-15.]

[ 9 ] Wu ML, Wang YS, Lin L et al. Study on changes characterization of water quality by principal component analysis in Daya Bay. Marine Environmental Science, 2009, 28(3): 279-282. [ 吴梅林, 王友紹, 林立等. 基于主成分分析研究大亚湾 水质时空变化特征. 海洋环境科学, 2009, 28(3) : 279-282.]

[10] Boyacioglu H. Surface water quality assessment using factor analysis. Water SA, 2006, 32(3) : 389-393.

[11] Liu DL, Liu XZ. Application of principal component analysis to the comprehensive evaluation of water quality in river. Reserch of Soil and Water Conservaion, 2006, 13(3): 124-128. [刘德林, 刘贤赵. 主成分分析在河流水质综合评价中 的应用. 水土保持研究, 2006, 13(3): 124-128.]

[12] Xu HS, Zhao L, Sun HS et al. Water quality analysis of Beijing segment of south-to-north water diversion middle route project. Environmental Science, 2017, 38(4): 1357-1364. [徐华山, 赵否, 孙吴苏等. 南水北调中线北京段水质状况分 析. 环境科学, 2017, 38(4): 1357-1364.]

[13] Chen HY, Liu MS, Yuan F et al. Analysis of relationship between microhabitat characteristics and major water quality indicators in littoral zone of Gonghu Bay, Tai Lake. Wetland Science, 2016, 19(4) : 580-585. [陈怀艳, 刘茂松, 袁芳等. 太湖贡湖湾滨岸带微生境特征与主要水质指标的关系分析. 湿地科学, 2016, 19(4): 580-585.]

[14] Li YG, Du HW, Huang YS et al eds. SPSS19.0 introduction and improvement of statistical analysis. Beijing: Tsinghua University Press, 2014: 308. [李玉光, 杜宏巍, 黄永生等. SPSS19.0 统计分析人门与提高. 北京: 清华大学出版社, 2014: 308.]

[15] Qi JY, Ruan XH. Dam construction-induced environmental impact on riverine ecosystem. Journal of Hohai University: Natural Sciences, 2005, 33(1): 37-40. [ 祁继英, 阮晓红. 大坝对河流生态系统的环境影响分析, 2005, 33(1): 37-40.]

[16] Yao HM, Huang RT, Gan FX et al. Principal component analysis of the water quality evaluation in East Lake. Geomatics and Information Science of Wuhan University, 2005, 30(82): 732-735. [姚焕玫, 黄仁涛, 甘复兴等. 用改进的主成分 分析法对东湖的水质污染进行评价. 武汉大学学报, 2005, 30(82): 732-735.]

[17] Jeong YH, Yang JS, Park K. Changes in water quality after the construction of an estuary dam in the Geum River estuary dam system, Korea. J Coastal Res, 2014, 298: 1278-1286.

[18] Mogakabe DE, Ginkel CV ed. The water quality of Bospoort Dam. Department of water affairs and forestry, South Africa, 2008.

[19] Lu JY, Huang Y, Wang J. The analysis on reservoir sediment deposition and downstream river channel scouring after impoundment and operation of TGP. Engineering Science, 2011, 13(7): 129-136. [卢金友, 黄悦, 王军. 三峡工程蓄水 运用后水库泥沙淤积及坝下游河道冲刷分析. 中国工程科学, 2011, 13(7): 129-136.]

[20] Ding XY, Zhou HD, Lei XH et al. Hydrological and associated pollution load simulation and estimation for the Three Gorges Reservoir of China. Stoch Environment Resource\& Risk Assessment, 2013, 27(3) : 617-628.

[21] Maavara T, Parsons CT, Ridenour C et al. Global phosphorus retention by river damming. Pro Natl Acad Sci USA, 2015, 112: $15603-15608$.

[22] Zhou JJ, Zhang M, Li Z. Dams altered Yangtze River phosphorus and restoration countermeasures. J Lake Sci, 2018,30 (4) : 865-880. DOI: 10.18307/2018.0401. [ 周建军, 张曼, 李哲. 长江上游水库改变干流磷通量、效应与修复对策. 湖泊科学, 2018, 30(4): 865-880.]

[23] Jiang L, Zhu DJ, Chen YC et al. Analysis on fecal coliform pollution in surface water of China. Advances in Science and Technology of Water Resources, 2015, 35(3): 11-18. [ 江否, 朱德军, 陈永灿等. 我国地表水体粪大肠菌群污染现状 分析. 水利水电科技进展, 2015, 35(3): 11-18.]

[24] Huang QC, Liu GL, Wang CY et al. Water quality variation characteristics of the main stream of the Three Gorges Reservoir under different water levels operation. Yangtze River, 2015, 46(s1) : 132-136. [黄庆超, 刘广龙, 王雨春等. 不同 水位运行下三峡库区干流水质变化特征. 人民长江, 2015, 46(s1): 132-136. ]

[25] Zhang S, Li CM, Lv PY et al. Spatial variation of $\mathrm{BOD}_{5}$ and $\mathrm{COD}_{\mathrm{Mn}}$ in the Three Gorges Reservoir. J Lake Sci, 2007,19 
(1) : 70-76. DOI: 10.18307/2007.0111. [张晟, 李崇明, 吕平觪等. 三峡水库成库后水体中 $\mathrm{COD}_{\mathrm{Mn}} 、 \mathrm{BOD}_{5}$ 空间变 化. 湖泊科学, 2007, 19(1): 70-76.]

[26] Zhang J, Yang ZY, Yang XX. A study on the relation between the turbidity degree of sewage and the concentration of $\mathrm{COD}_{\mathrm{Cr}}, \mathrm{BOD}_{5}$ and coliform bacteria. Modern Preventive Medicine, 2004, 31(4): 505-512. [张静, 杨正炎, 杨湘霞. 生 活污水浑浊度与 $\mathrm{COD}_{\mathrm{Cr}} 、 \mathrm{BOD}_{5}$ 及粪大肠菌群浓度的关系. 现代预防医学, 2004, 31(4) : 505-512.]

[27] Xing CX. Analysis of sulfate change for Huangbizhuang Reservoir and Gangnan Reservoir. South-to-North Water Transfers and Water Science \& Technology, 2013, 11(1) : 66-67. [邢晨䂀. 黄壁庄和岗南水库硫酸盐变化规律分析. 南水北调 与水利科技, 2013, 11(1): 66-67.]

[28] Editorial board of "water and wastewater monitoring and analysis method", Ministry of Environmental Protection of the People's Republic of China ed. Monitoring and analysis methods of water and wastewater: fourth edition. Beijing: China Environmental Science Press, 2002. [ 国家环境保护总局《水和废水监测分析方法》编委会. 水和废水监测分析方 法: 第 4 版. 北京: 中国环境科学出版社, 2002.]

[29] Zhang JS, Zhang Y, Yu T et al. Influences of the suspended matter on the water quality parameters including COD, Potassium Permanganate Index and $\mathrm{BOD}_{5}$ in the Yellow River, China. Acta Scientiae Circumstantiae, 2004, 24(3) : 70-76. [张静生, 张宇, 于涛等. 泥沙对黄河水质参数 $\mathrm{COD}$ 、高锰酸钾指数和 $\mathrm{BOD}_{5}$ 的影响——三论黄河的 $\mathrm{COD}$ 与高锰 酸盐指数不能真实反映其污染状况. 环境科学学报, 2004, 24(3): 70-76.]

[30] Chen JS, Xia XH, Zhang LT et al. Relationship between water quality changes in the Yangtze, Yellow and Songhua Rivers and the economic development in the river basins. Acta Scientiae Circumstantiae, 1999, 19(5) : 500-505. [陈静生, 夏星 辉, 张利田等. 长江、黄河、松花江 60-80 年代水质变化趋势与社会经济发展的关系. 环境科学学报, 1999, 19(5): 500-505.]

[31] Chen JS, Guan WR, Xia XH et al. A probe into several problems of water-quality trends in the mainstream of Yangtze river from 1960's to1980s. Environmental Chemistry, 1998, 17(1) : 8-13. [陈静生, 关文荣, 夏星辉等. 长江干流近三十 年来水质变化探析. 环境化学, 1998, 17(1):8-13.]

[32] Wang JS, Bian JJ, Chen XG. Analysis on changing tendency of water quality in trunk stream of Yangtze River since 2000. Hubei Water Power, 2009, (2) : 1-3. [汪金成, 市俊杰, 陈新国. 2000 年以来长江干流水质变化趋势分析. 湖北水 利发电, 2009, (2): 1-3.]

[33] Dai RQ, Zang XP, Qiu GS. Water quality in the Three Gorges Reservoir before impoundment. Resources and Environment in the Yangtze Basin, 2004, 13(2): 124-127. [戴润泉, 㶓小平, 邱光胜. 三峡水库蓄水前库区水质状况研究. 长江 流域资源与环境, 2004, 13(2): 124-127.]

[34] Chen YC, Fu J, Liu ZW et al. Evaluation of water quality near the dam before and after the storage of Three Gorges Reservoir. Journal of Hydroelectric Engineering, 2007, 26(4) : 51-55. [陈永灿, 付健, 刘昭伟. 三峡水库蓄水前后近坝水 域的水质评价与分析. 水利发电学报, 2007, 26(4): 51-55.]

[35] Liu XB, Liu XX, Fu DL. Analysis on water quality variation of the mainstream and tributaries in Wushan section, Three Gorges Reservoir region. Environmental Science and Management, 2010, 35(5): 124-125. [刘学斌, 刘晓霞, 傅道林. 三峡工程库区巫山段干支流水质变化分析研究. 水利发电学报, 2010, 35(5): 124-125.]

[36] Peng FL, He LH, Yu Y et al. Studies on the total nitrogen, total phosphorus and chlorophyll a variations in the mainstream and main tributaries of the Yangtze River before and after the impoundment in the Three Gorges Project area. Scientia Sinica Technologica, 2017, 47(8) : 845-853. [彭福利, 何立环, 于洋等. 三峡库区长江干流及主要支流氮磷叶绿素变 化趋势研究. 中国科学: 科技科学, 2017, 47(8): 845-853.] 


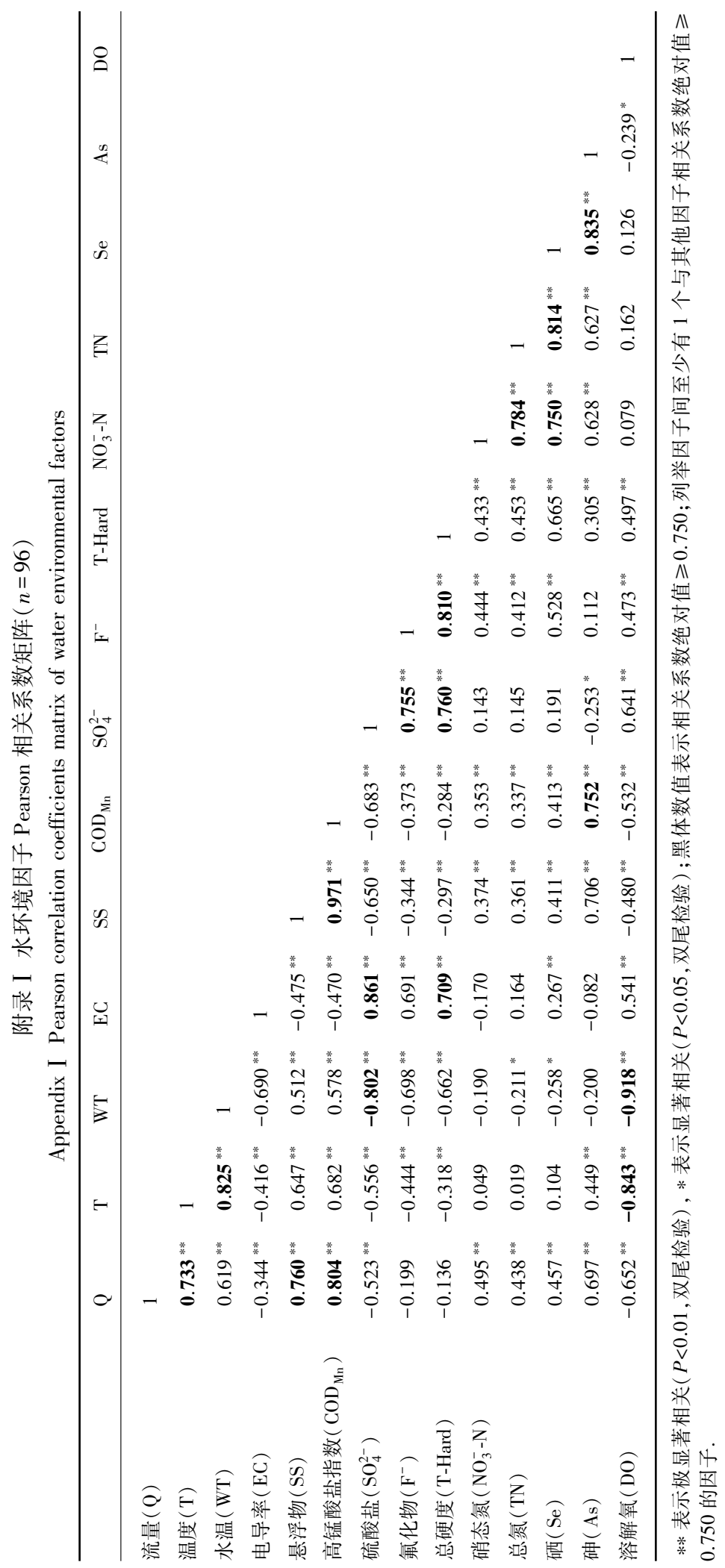

